Article

\title{
Water Transfer Characteristics during Methane Hydrate Formation Processes in Layered Media
}

\section{Peng Zhang *, Qingbai Wu, Yibin Pu and Yousheng Deng}

State Key Laboratory, Cold and Arid Regions Environmental and Engineering Research Institute, Chinese Academy of Sciences, Lanzhou 730000, Gansu, China; E-Mails: qbwu@lzb.ac.cn (Q.W.); pybin@1zb.ac.cn (Y.P.); dengys@1zb.ac.cn (Y.D.)

* Author to whom correspondence should be addressed; E-Mail: zhangpeng@1zb.ac.cn; Tel.: +86-931-4967887; Fax: +86-931-4967284.

Received: 7 June 2011; in revised form: 26 July 2011 / Accepted: 27 July 2011 /

Published: 2 August 2011

\begin{abstract}
Gas hydrate formation processes in porous media are always accompanied by water transfer. To study the transfer characteristics comprehensively, two kinds of layered media consisting of coarse sand and loess were used to form methane hydrate in them. An apparatus with three PF-meter sensors detecting water content and temperature changes in media during the formation processes was applied to study the water transfer characteristics. It was experimentally observed that the hydrate formation configurations in different layered media were similar; however, the water transfer characteristics and water conversion ratios were different.
\end{abstract}

Keywords: methane hydrate; formation; water transfer; layered media

\section{Introduction}

Clathrate hydrates, firstly identified by Sir Humphrey Davy in 1810 [1] are solid, non-stoichiometric compounds consisting of polyhedral water cavities and small gas molecules in the cavities [2], which have great potential as a premium source of natural gas, and have therefore attracted the wide interest of many researchers and governments. Geophysical and geological investigations have verified that large masses of natural gas hydrates exist in the sediments beneath permafrost regions and deep oceans. Some of them are in the bulk form and others are in the form of inclusions within sediments or 
cemented soils [3]. Gas hydrate formation and decomposition conditions can be seriously affected by the surrounding sediments. Therefore, knowledge about the thermodynamic mechanism(s) of formation and dissociation of hydrates in porous media is significant for research on gas hydrate storage and exploitation [4]. Many researchers have done much work based on this knowledge [5-8] and many study results have presented the fundamental pressure/temperature conditions properties of hydrate formation and dissociation in media [9-15].

In porous media, the gas hydrate formation configuration is similar to that of ice freezing [7]: in fine-grain sediments, gas hydrate aggregation is like ice-lens [16]; in coarse-grain sediments, "freeze-dry" phenomenon can be observed during hydrate formation processes [17]. Chuvilin [18] first studied the water transfer behavior during gas hydrate formation process in porous media with a weighing method. After that, Kneafsey [19], Jin Shigeki [20] and Kawasaki Tatsuji [21] confirmed that gas hydrate formation processes were always accompanied by water transfer behavior inside porous media using the computer tomography technology. However, during all the studies with computer tomography, water transfer behavior in porous media was researched not in the media, but just from outside of media; otherwise, all the experimental media were homogeneous. Up to now, during gas hydrate formation processes, direct studies on water transfer behavior inside nonhomogeneous porous media have not been reported.

In this study, an apparatus with three PF-meter sensors to detect water content and temperature changes in the porous media was assembled and the water transfer characteristics during methane hydrate formation processes were studied. The apparatus has been applied to our previous water transfer studies on methane hydrate formation and dissociation processes [22,23]. Coarse sand and loess were chosen to prepare layered sediments, in which methane hydrate was formed by cooling and the water transfer characteristics during the hydrate formation processes were studied.

\section{Procedure}

\subsection{Experimental Apparatus}

As shown in Figure 1, the experimental apparatus was composed of methane gas supplying system, reaction system and data-logging system. Methane gas (Hongzhuo Chemical Co., Ltd., Chengdu, China) was stored in a gas cylinder and its purity was $99.99 \%$. The reaction system was composed of a low-temperature bath $\left(-10 \sim 80 \pm 0.05{ }^{\circ} \mathrm{C}\right)$, a coolant temperature sensor $\left(-20 \sim 30 \pm 0.02{ }^{\circ} \mathrm{C}\right)$ inside the bath, a reaction cell and three PF-meter sensors which were vertically embedded in the top, middle and bottom core positions in the porous media respectively and all them were in the middle of each layer. The data-logging system was composed of two computers, which continuously logged gas pressure $(0 \sim 10 \pm 0.02 \mathrm{MPa})$ and coolant temperature $\left(-20 \sim 30 \pm 0.02{ }^{\circ} \mathrm{C}\right)$; and PF values $(0 \sim 7 \pm 0.05 \mathrm{PF})$ and media temperature $\left(-40 \sim 60 \pm 0.05{ }^{\circ} \mathrm{C}\right)$ respectively. The reaction cell was a stainless steel cylinder and could be used in $0 \sim 20 \mathrm{MPa}$ and $-50 \sim 100{ }^{\circ} \mathrm{C}$ ranges (height $19.5 \mathrm{~cm}$, diameter $10.0 \mathrm{~cm}$, volume $1400 \mathrm{~cm}^{3}$ ). The working principle of PF-meter sensor (Germanic GEO-Precision Environment Technology Company, Karlsruhe, Germany) is based on the fact that the heat capacity of soil can be determined by heating the soil sample. If a variation of water content in soil occurs, heat capacity directly measured by the PF-meter sensor will produce a relative change. The relationship between the 
PF values of PF-meter $(0 \sim 7 \pm 0.05 \mathrm{PF})$ and water content of media is absolutely linear. When water content in media increased or decreased, PF values will fall or rise. The PF values show 0 PF when mediais saturated and 7 PF when media is completely dry, and PF means picofarad [24]. So, the water content changes can be indicated by the PF value changes and the water transfer characteristics can be analyzed. In addition, PF-meter sensors could directly detect the temperature in media during the experiments, simultaneously.

Figure 1. Schematic diagram of the experimental apparatus. 1. Gas cylinder; 2. Gas valve; 3. Pressure gauge; 4. Gas valve; 5. Gas line; 6. Reaction cell; 7. PF-meter sensors, length $=7 \mathrm{~cm}$, diameter $=2 \mathrm{~cm} ; 8$. Coolant temperature sensor; 9. Low-temperature batch; 10. Data-logging system of pressure value and coolant temperature; 11. Data-logging system of PF value and temperature inside cell.

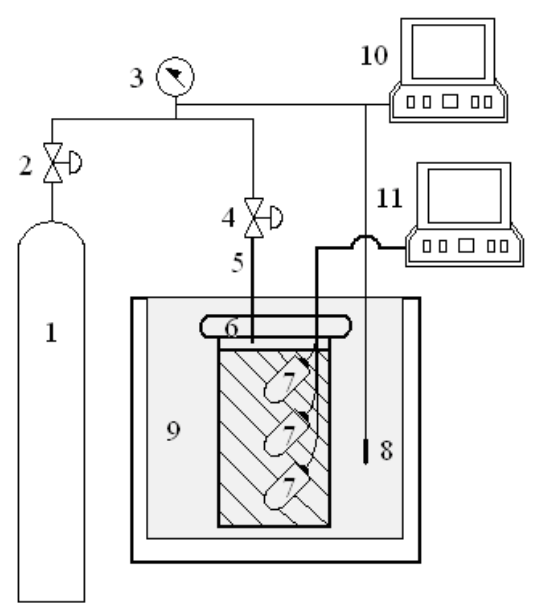

\subsection{Experimental Procedures}

In our experiments, coarse sand with 1.0-2.0 $\mathrm{mm}$ average particle size and loess were chosen to prepare the layered media. With a particle size analyzer, average particle size of loess was confirmed as $34.5 \times 10^{-3} \mathrm{~mm}$. Before experiments, the pre-media were soaked in excess deionized water for more than $48 \mathrm{~h}$ to remove the soluble substances and then were dried by heat. After that, two kinds of three-layered media were assembled. The water content of the half-saturated pre-media was only a half of that of the saturated, which was listed in Table 1. One type assembled a layer of saturated loess on top, half-saturated coarse sand in the middle, and saturated loess at the bottom. The second type assembled a layer of half-saturated coarse sand on top, saturated loess in the middle, and half-saturated coarse sand at the bottom. With the method in reference [25], the pre-media were saturated with deionized water.

Table 1. Physical properties of experimental porous media.

\begin{tabular}{cccccc}
\hline Media & $\begin{array}{c}\text { Particle size } \\
(\mathbf{m m})\end{array}$ & $\begin{array}{c}\text { Each Layer } \\
\text { Weight }(\mathbf{g})\end{array}$ & $\begin{array}{c}\text { Each } \\
\text { LayerHeight } \\
(\mathbf{c m})\end{array}$ & $\begin{array}{c}\text { Saturated } \\
\text { Water Content (\%) }\end{array}$ & $\begin{array}{c}\text { Half-Saturated } \\
\text { Water Content (\%) }\end{array}$ \\
\hline $\begin{array}{c}\text { Coarse sand } \\
\text { Loess }\end{array}$ & $1.0-2.0$ & 520.0 & 4.0 & 14.0 & 7.0 \\
\hline
\end{tabular}


When the layered media were filled into the reaction cell, three PF-meter sensors were embedded in each layer and the PF values of the whole layer rather than those at their positions were measured. After that, the reaction system was remained stable for a period of time under atmospheric pressure, in order to allow the water content of the different layers to reach a balance. Then, the reaction system was evacuated, and methane gas was slowly injected into the reaction cell until it reached the predesigned pressure. The temperature was then reduced from $12{ }^{\circ} \mathrm{C}$ (theoretical methane hydrate stability pressure $9.019 \mathrm{MPa}$ ) to $0.5^{\circ} \mathrm{C}$ (theoretical methane hydrate stability pressure $2.729 \mathrm{MPa}$ ) at a cooling rate of about $2.3{ }^{\circ} \mathrm{C} / \mathrm{h}$ to form methane hydrate in the media. During the formation processes, the three PF-meter sensors could indicate the water content changes and the water transfer characteristics could be analyzed.

Before this study, several experiments on methane hydrate formation configurations in media and water transfer characteristics during methane hydrate formation processes were conducted by us [22-24]. In accordance with previous experimental results, we ensured that the reproducibility of our experiments was very good, so the same formation experiments were repeated twice. The first one was to measure the experimental parameter changes and the second was to study the hydrate configuration. After the second were completed, high-pressure methane gas was rapidly released and the layered media bearing methane hydrate were rapidly taken out and the photographs of hydrate configuration were taken. Thus, the water transfer characteristics during the hydrate formation processes could be analyzed comprehensively.

\section{Results and Discussion}

\subsection{Methane Hydrate Formation Configuration}

Figure 2 shows photographs of hydrate formation configuration inside media. As shown, although the layered media were different, the configurations of hydrate formation were largely similar. Whether the saturated loess was in the middle or on top and bottom positions, methane hydrate was formed only in the sand layers and the sand particles were tightly cemented together. However, there was no methane hydrate inside loess layers during our two formation experiments: there were no hydrate particles and cementation inside it and the loess was very spongy. According to the pressure and temperature changes, the water conversion ratios in two experiments were calculated and listed in Figure 2, which indicated that the amount of non-saturated coarse sand was helpful for the hydrate formation in the layered media. After the formation experiments, loess layers were much drier than the initial stage, indicating that hydrate formation could cause a kind of suction in the water in the saturated loess and a large amount of water was drawn out of loess. 
Figure 2. Photographs of hydrate configuration in different layered media (water conversion ratio in the left is $23.1 \%$ and that in the right is $16.2 \%$ ).
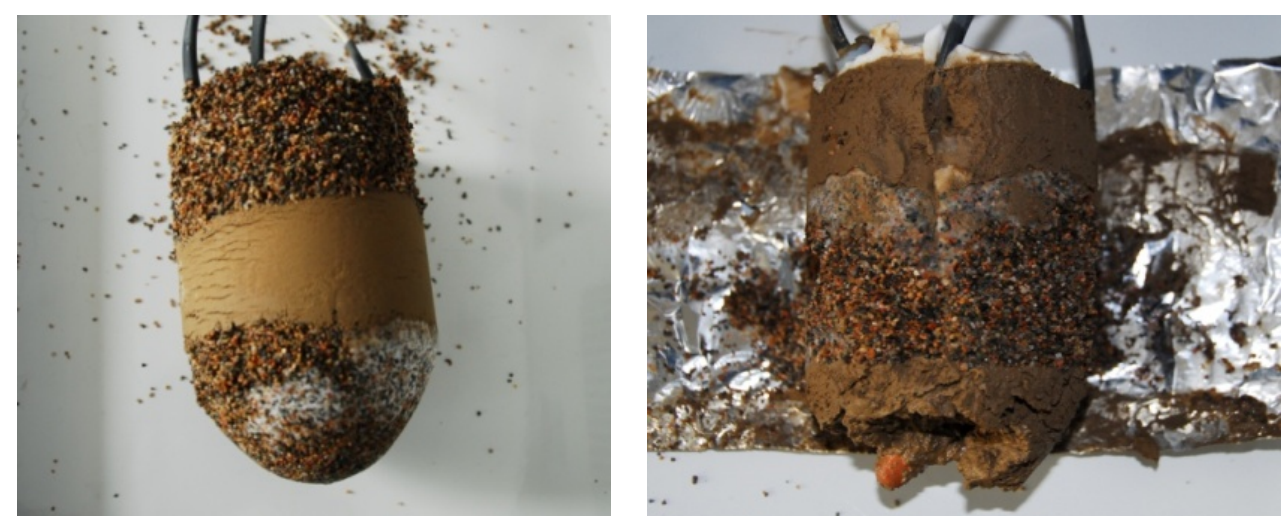

\subsection{Methane Hydrate Formation Inside the Layered Medium}

\subsubsection{Top Coarse Sand, Middle Loess and Bottom Coarse Sand Layered Medium}

The parameter changes during stabilization of the system and the experiment processes are shown in Figure 3. As shown in Figure 3a, during the stabilization process under atmospheric pressure, the top and bottom PF values rapidly fell to 0 PF over $0-7 \mathrm{~h}$, indicating that a large amount of water rapidly diffused to the half-saturated coarse sand from the saturated loess. Following the high-pressure methane gas injection at $11.5 \mathrm{~h}$, top and bottom PF values abruptly jumped to $1.49 \mathrm{PF}$ and $0.43 \mathrm{PF}$, indicating that because the sand layer was drastically squeezed by the high-pressure gas, water inside it was extruded. At $20 \mathrm{~h}$, the temperature began reducing to $0.5^{\circ} \mathrm{C}$ and Figure $3 \mathrm{~b}$ shows the parameter changes during the process. Temperature in top layer slightly rose at $23 \mathrm{~h}$ and the temperature curves for middle and bottom layers did not represent abnormity. Considering the left photograph in Figure 2, the fact that methane hydrate was formed only in top coarse sand layer was confirmed. Figure $3 \mathrm{~b}$ also shows that following hydrate formation, PF values of both top and bottom layers abruptly fell to $0 \mathrm{PF}$ from 1.46 PF and 0.46 PF, respectively. After that, the middle and bottom PF values rapidly rose and the top PF value remained at 0 PF constantly. Those indicated that because methane hydrate was formed only in the top layer, a kind of suction of water was caused, and water was drawn to it from the middle and bottom layer. The suction is derived from the fact that while the hydrate was formed, water rapidly migrated to the hydrate surface with lower Gibbs free energy [26].

After the temperature was reduced to $0.5{ }^{\circ} \mathrm{C}$, it remained stable. Over $23-26 \mathrm{~h}$, because of the hydrate formation, the water inside the middle and bottom layers was drawn to top. Over $26-33 \mathrm{~h}$, the bottom PF value rapidly fell and the middle PF value remained rising, indicating that methane hydrate started to form inside the bottom layer and the water in the middle layer was drawn to the bottom. At $34 \mathrm{~h}$, the bottom PF values abruptly jumped to 1.56 PF from 0 PF, and top PF fell to 2.07 PF from 2.69 PF, indicating that water inside bottom layer was rapidly depleted by hydrate formation and the water inside top layer was drawn down to bottom layer through the middle. At $39 \mathrm{~h}$, the top PF value also abruptly jumped to $1.96 \mathrm{PF}$ from $0 \mathrm{PF}$, indicating that methane hydrate was forming inside the top layer again and a large amount of water was depleted. Over $43-50 \mathrm{~h}$, the top and bottom PF values rapidly fell to $0 \mathrm{PF}$, indicating that a large amount of water rapidly transferred to the top and bottom 
layers. Over $60-68 \mathrm{~h}$, the middle PF value rapidly fell to $0 \mathrm{PF}$, indicating that methane hydrate formation tended to be completed.

Figure 3. Parameter changes during methane hydrate formation process in the layered medium: top coarse sand layer, middle loess layer and bottom coarse sand layer: (a) PF value and pressure changes during the whole experiment process; (b) Temperature and $\mathrm{PF}$ value changes during cooling process.

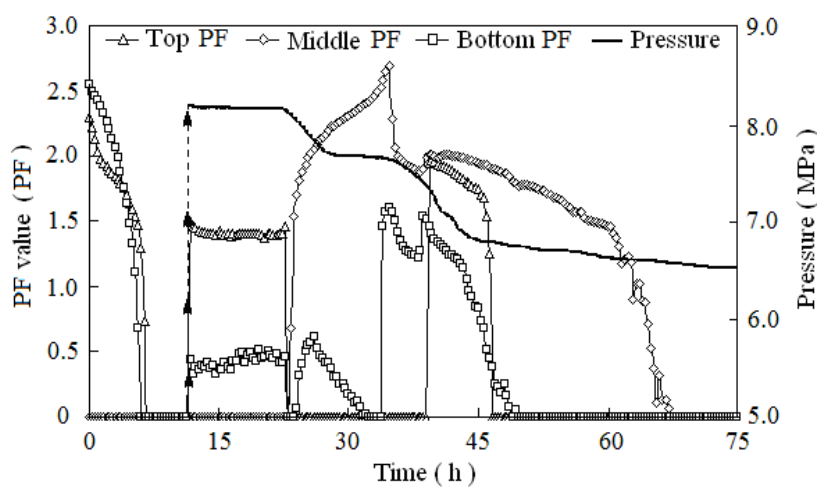

(a)

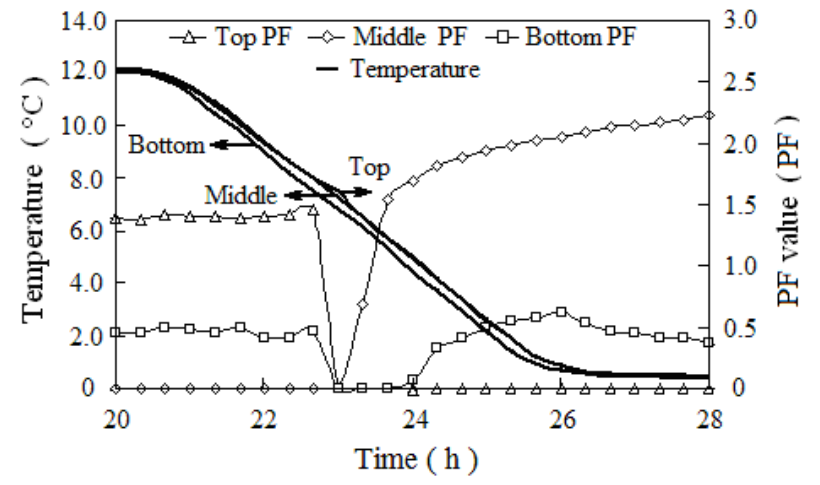

(b)

\subsubsection{Top Loess, Middle Coarse Sand and Bottom Loess Layered Medium}

Figure 4 shows the parameter changes in the other layered medium. In Figure $4 \mathrm{a}$, the reaction system was retained and PF values in middle layer rapidly fell to $2.85 \mathrm{PF}$, indicating that during the process, some water rapidly moved to the middle half-saturated coarse sand layer from loess. At $23.5 \mathrm{~h}$, high-pressure methane gas was slowly injected and the temperature was reduced to $0.5{ }^{\circ} \mathrm{C}$ over 30-35 h. As shown in Figure 4b, only the middle temperature obviously rose at $32.5 \mathrm{~h}$, indicating that methane hydrate was formed only inside the middle layer. Figure $4 \mathrm{~b}$ also shows that the top and bottom PF values obviously rose at $32.5 \mathrm{~h}$, indicating that water inside top and bottom loess layers was drawn to the middle layer. As shown in Figure $4 \mathrm{a}$, the wave changes of middle PF values over 32.5-45 h were due to the water depletion caused by hydrate formation and the water supply caused by the water transfer to coarse sand from loess. After that, top PF values rapidly fell to $0 \mathrm{PF}$ over $68-72 \mathrm{~h}$ and bottom PF values slowly fell to 0 PF over 88-112 h, indicating that methane hydrate formation process tended to be completed.

Comparing Figure 4 with Figure 3, it was found that although the configurations of methane hydrate formation inside different layered media were similar, the water transfer characteristics were different, which indicated that the processes could be seriously affected by media type. Under the same conditions, disseminated hydrate could not be formed inside saturated loess but only inside half-saturated coarse sand, indicating that hydrate formations are affected by water contents of media. According to our previous experiments, methane hydrates were easily formed inside non-saturated coarse sand and loess; however, their formation inside the saturated was very difficult [22-24]. In this study, coarse sand layer was non-saturated and loess layer was saturated, so crystals were easier to form in the coarser media, and could grow with pulling in water from the finer sediments. 
Figure 4. Parameter changes during methane hydrate formation process in the layered medium: top loess layer, middle coarse sand layer and bottom loess layer (a) PF value and pressure changes during the whole experiment process; (b) Temperature and PF value changes during cooling process.

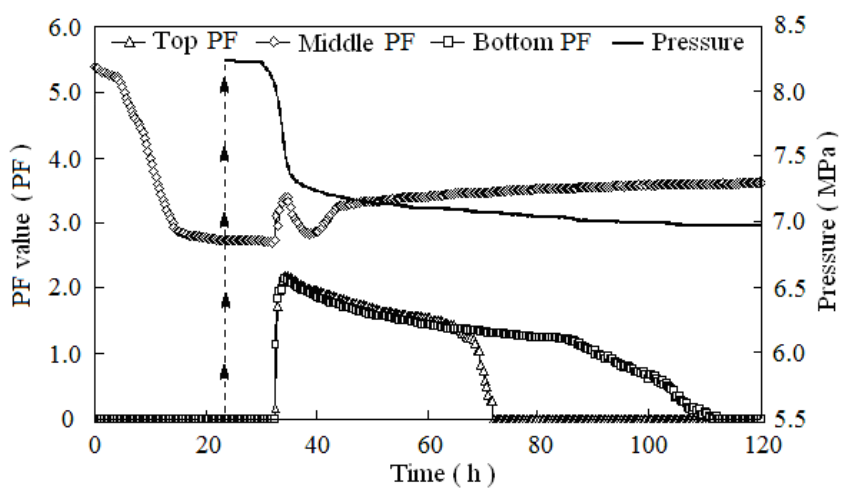

(a)

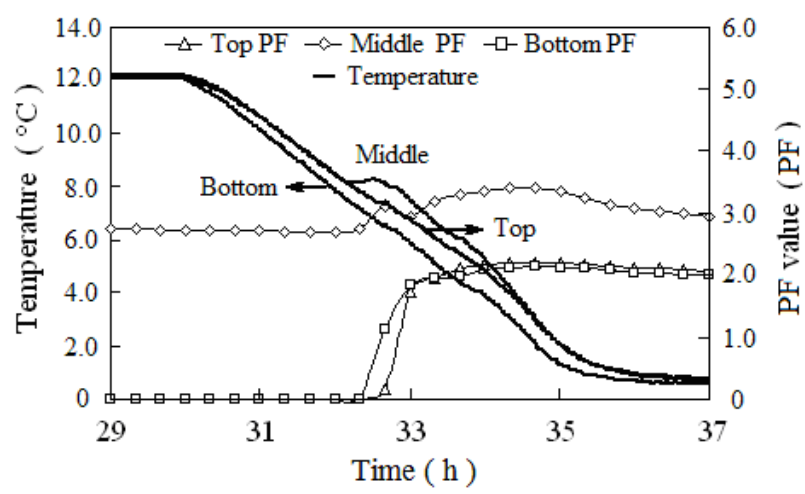

(b)

\section{Conclusions}

Using coarse sand and loess, two kinds of layered media were prepared to study the water transfer characteristics during methane hydrate formation processes in them. Based on an apparatus with three PF-meter sensors, the water transfer characteristics in the layered media were studied successfully. The results showed experimentally that in two different layered media, the hydrate formation configurations were similar: methane hydrate was formed only inside coarse sand. However, the water transfer characteristics and the water conversion ratios inside different media were quite different. In the layered medium consisting of two half-saturated coarse sand layers and one saturated loess layer, methane hydrate was formed in the following order: first in the top coarse sand layer; followed by the bottom coarse sand layer; then all over again in the top coarse sand layer. However, in the other medium consisting of two saturated loess layers and one half-saturated coarse sand layer, methane hydrate was formed only in the middle coarse sand layer and the water was transferred to the coarse sand layer from the two loess layers. Thus, water transfer characteristics following hydrate formation processes can be seriously affected by media types. In addition, methane hydrate formation configurations are affected by the water content of the media and the amount of non-saturated coarse sand was helpful for the hydrate formation in the layered. The studies on water transfer characteristics during hydrate formation processes in media were helpful for understanding the formation mechanism of natural gas hydrates comprehensively.

\section{Acknowledgements}

The authors thank two anonymous reviewers for their helpful comments. This work was financially supported by the CAS West Action Plan (Grant No. KZCX2-XB3-03), the Training Fund of State Key Laboratory of Frozen Soil Engineering of Chinese Academy of Sciences (Grant No. 52YOSF102), and the Foundation for Excellent Youth Scholars of CAREERI, CAS (Grant No. Y184A41001). 


\section{References}

1. Koh, C.A. Towards a fundamental understanding of natural gas hydrates. Chem. Soc. Rev. 2002, 31, 157-167.

2. Sloan, E.D. Fundamental principles and applications of natural gas hydrates. Nature 2003, 426, 353-359.

3. Turner, D.; Sloan, E.D. Hydrate Phase Equilibria Measurements and Predictions in Sediments. In Proceedings of the Fourth International Conference on Gas Hydrates, Yokohama, Japan, 19-23 May 2002.

4. Handa, Y.P.; Stupin, D. Thermodynamic properties and dissociation characteristics of methane and propane hydrates in 70-Å-radius silica gel pores. J. Phys. Chem. 1992, 96, 8599-8603.

5. Melnikov, V.; Nesterov, A. Modeling of Gas Hydrate Formation in Porous Medium. In Proceedings of the Second International Conference on Gas Hydrates, Toulouse, France, 2-6 June 1996.

6. Melnikov, V.P.; Nesterov A.N. Gas hydrate formation in mineralized pore water. Earth Cryosphere 2001, 5, 3-14.

7. Henry, P.; Thomas, M.; Clennell, M.B. Formation of natural gas hydrates in marine sediments 2, thermodynamic calculations of stability conditions in porous sediments. J. Geophys. Res. 1999, 104, 23005-23012.

8. Clarke, M.A.; Pooladi-Darvish, M.; Bishnoi, P.R. A method to predict equilibrium conditions of gas hydrate formation in porous medium. Ind. Eng. Chem. Res. 1999, 38, 2485-2490.

9. Uchida, T.; Ebinuma, T.; Ishizaki, T. Dissociation condition measurements of methane hydrate in confined small pores of porous glass. J. Phys. Chem. B 1999, 103, 3659-3662.

10. Uchida, T.; Ebinuma, T.; Takeya, S.; Nagao, J.; Narita, H. Effects of pore sizes on dissociation temperatures and pressures of methane, carbon dioxide and propane hydrate in porous media. J. Phys. Chem. B 2002, 106, 820-826.

11. Uchida, T.; Takeya, S.; Chuvilin, E.M.; Nagao, J.; Yakushev, V.S.; Istomin, V.A.; Minagawa, H.; Ebinuma, T.; Narita, H. Decomposition of methane hydrates in sand, sandstone, clays, and glass beads. J. Geophys. Res. 2004, 109, B05206.1-B05206.12.

12. Clennell, M.B.; Hovland, M.; Booth, J.S.; Henry, P.; Winters, W.J. Formation of natural gas hydrates in marine sediments 1 , conceptual model of gas hydrate growth conditioned by host sediment properties. J. Geophys. Res. 1999, 104, 22985-23003.

13. Ostergaard, K.K.; Anderson, R.; Llamedo, M.; Tohidi, B. Hydrate phase equilibrium in porous media: Effect of pore size and salinity. Terra Nova 2002, 14, 307-312.

14. Anderson, R.; Llamedo, M.; Tohidi, B.; Burgass, R.W. Characteristics of clathrate hydrate equilibrium in mesopores and interpretation of experimental data. J. Phys. Chem. A 2003, 107, 3500-3506.

15. Anderson, R.; Llamedo, M.; Tohidi, B.; Burgass, R.W. Experimental measurement of methane and carbon dioxide clathrate hydrate equilibrium in mesoporous silica. J. Phys. Chem. B 2003, 107, 3507-3514.

16. MacDonald, I.R.; Guninasso, N.L.; Sassen, R.; Brooks, J.M.; Lee, L.; Scott, K.T. Gas hydrate that breaches the sea floor on the continental slope of the Gulf of Mexico. Geology 1994, 22, 699-702. 
17. Pearson, C.F.; Halleck, P.M.; McGuire, P.L.; Hermes, R.; Mathews, M. Natural gas hydrates: A review of in situ properties. J. Phys. Chem. 1983, 87, 4180-4185.

18. Chuvilin, E.M.; Yakushev, V.S.; Perlova, E.V. Experimental study of gas hydrate formation in porous media. In Advances in Cold-Region Thermal Engineering and Sciences; Springer: Berlin, Germany, 1999; Volume 533, pp. 431-440.

19. Kneafsey, T.J.; Tomutsa, L.; Moridis, G.J.; Seol, Y.; Freifeld, B.M.; Taylor C.E.; Gupta, A. Methane hydrate formation and dissociation in a partially saturated core-scale sand sample. J. Pet. Sci. Eng. 2007, 56, 108-126.

20. Jin, S.; Takeya, S.; Hayashi, J.; Nagao, J.; Kamata, Y.; Ebinuma, T. Structure Analyses of Methane Hydrate Sediments by Microfocus X-ray CT. In Proceedings of the Fifth International Conference on Gas Hydrates, Trondheim, Norway, 12-16 June 2005.

21. Kawasaki, T.; Tsuchiya, Y.; Nakamizu, M. Observation of Methane Hydrate Dissociation Behavior in Methane Hydrate Bearing Sediments by X-ray CT Scanner. In Proceedings of the Fifth International Conference on Gas Hydrates, Trondheim, Norway, 12-16 June 2005.

22. Zhang, P.; Wu, Q.B.; Pu, Y.B.; Jiang, G.L.; Zhan, J.; Wang, Y.M. Water transfer characteristics during methane hydrate formation and dissociation processes inside saturated sand. J. Nat. Gas Chem. 2010, 19, 71-76.

23. Zhang, P.; Wu, Q.B.; Jiang, G.L.; Zhan, J.; Wang, Y.M. Water transfer characteristics in the vertical direction during methane hydrate formation and dissociation processes inside non-saturated media. J. Nat. Gas Chem. 2010, 19, 139-145.

24. Zhang, P.; Wu, Q.B.; Wang, Y.M. Comparison of the water change characteristics between the formation and dissociation of methane hydrate and the freezing and thawing of ice in sand. J. Nat. Gas Chem. 2009, 18, 205-210.

25. Deng, Y.S.; Xu, X.Z. Hydraulic conductivity of unsaturated soil and its changing regularity in saturated soil after freezing-thawing cycles. J. Glaciol. Geocryol. 1991, 13, 51-59.

26. Sloan, E.D. Clathrate Hydrates of Natural Gases, 2nd ed.; CRC Press: New York, NY, USA, 1998.

(C) 2011 by the authors; licensee MDPI, Basel, Switzerland. This article is an open access article distributed under the terms and conditions of the Creative Commons Attribution license (http://creativecommons.org/licenses/by/3.0/). 